\title{
EMBRACING THE UNEXPECTED: USING TROUBLESHOOTING TO MODULATE STRUCTURED- TO OPEN-INQUIRY AND SELF- REGULATED LEARNING IN A FIRST-YEAR VIRTUAL LAB
}

\author{
Zarah Chaudhary ${ }^{l}$ and Gabrielle Lam ${ }^{2,3}$ \\ ${ }^{1}$ Department of Educational and Counselling Psychology, and Special Education, \\ ${ }^{2}$ School of Biomedical Engineering and ${ }^{3}$ Department of Materials Engineering \\ University of British Columbia, Canada \\ Corresponding Author E-mail: gabrielle.lam@ubc.ca
}

\begin{abstract}
The implementation of inquiry-based learning in the first-year laboratory curriculum is a significant challenge, due to students' limited exposure to unstructured learning. In this course, troubleshooting activities were used to modulate student progression from structured- to guided-, and finally to open-inquiry in a virtual first-year laboratory course. The purpose of the study is to investigate the effect of modulating student progression from structured- to open-inquiry on student development of self-regulated learning skills. The study presents preliminary survey results regarding student engagement in structured-inquiry activities. Analysis of survey results from guided-and open-inquiry activities, as well as qualitative analysis of student reflection assignments are currently ongoing.
\end{abstract}

Keywords: Self-regulated learning, inquiry-based learning, troubleshooting, laboratory, first-year engineering

\section{INTRODUCTION}

\subsection{Study motivation}

Inquiry-based learning (IBL) is a constructivist, studentcentered approach that engages students in "the discovery process of a scientist" [1]. Its implementation in laboratory curricula has been studied in various undergraduate contexts, with evidence indicating positive impacts on student achievement of learning outcomes and confidence in executing research-related tasks [2-4]. However, its implementation in the first-year engineering context presents unique challenges, because students have had little prior exposure to unstructured learning, and are in the early stages of developing domain-specific knowledge. Moreover, with the recent shift to online education, implementation of inquiry-based learning in the online learning environment presents significant challenges.

Post-secondary educators have learned to embrace both the advantages and limitations of virtual laboratories. On the one hand, they can be less resource-intensive, more accessible to students in different locations, and can offer students the flexibility to work at their own pace [5]. In fact, some comparative studies have shown no significant difference in academic performance between students completing hands-on versus virtual laboratory courses $[6,7]$. However, compared to physical labs, virtual ones are less effective in facilitating students' development of skills to "make sense of imperfect measurements" and to "learn about complexities and unanticipated events" [8]. Interestingly, this observation is also made by students themselves. Findings by Jeffrey et al. in a study investigating student perceptions of physical versus virtual chemistry laboratories indicated that students perceived virtual labs as being less effective due to fewer opportunities to learn from making mistakes and unexpected outcomes [9].

Troubleshooting is a type of problem solving which "requires an individual to diagnose faulty systems and take direct, corrective action to eliminate any faults in order to return the systems to their normal states", and is an integral skill of a practicing engineer [10]. According to a cognitive model of troubleshooting by Jonnasen and Hung, the process involves constructing a problem space, identifying faulty symptoms, diagnosing faults, generating and verifying solutions, and remembering the experience [10]. Self-regulation, which refers to "self-generated thoughts, 
feelings and actions that are planned and cyclically adapted to the attainment of personal goals" [11], therefore plays a key role in troubleshooting [12].

Although troubleshooting facilitates a "shift from conceptual understanding to experiential understanding" [10], it is more commonly utilized in hands-on upper-year laboratories, particularly to teach circuit analysis in electrical engineering. It is rarely used in the first-year laboratory curriculum, and even less so in virtual laboratories. In this study, a first-year laboratory course was designed to modulate student progression from guided- to open-inquiry laboratory activities, with the gradual implementation of trouble-shooting activities in the virtual learning environment. Here, the purpose is to determine the effect of modulating student progression from structured- to open-inquiry laboratory activities on their development of self-regulated learning (SRL) skills, in the context of a first-year virtual laboratory course.

\subsection{Conceptual framework for studying self- regulated learning}

There are multiple conceptual frameworks that can be used to investigate self-regulated learning; their key differences lie in the components of self-regulation emphasized. The conceptual framework used in this study is based on a social cognitive approach, which views self-regulation as the interaction between personal, behavioral and environmental processes [11].

According to Zimmerman's cyclical phase model, selfregulation involves three interconnected stages: forethought, performance and self reflection [13]. These phases are proposed to be cyclically sustained, where feedback from a past performance is used to adjust subsequent performance. The forethought phase involves two closely related categories: task analysis and selfmotivational beliefs [13]. Task analysis involves goal setting and strategic planning, while self-motivational beliefs include self-efficacy assessment, outcome expectations, task interest and value, and goal orientation [13]. The performance phase involves two categories: selfobservation and self-control [13]. Self-observation includes metacognitive monitoring and self-recording, while self-control involves defining task strategies, selfinstruction, time management, environmental structuring, help-seeking, interest incentives and self-consequences [13]. In the final phase of self-reflection, individuals assess their work and react to their self-judgements [13]. Selfjudgment involves self-evaluation and causal attribution, while self-reaction involves self-satisfaction and affect, as well as adaptive or defensive decisions [13].

CEEA-ACEG21; Paper 104

University of Prince Edward Island; June 21 - 23, 2021- 2 of 7 -

\subsection{Significance of results}

Results from this study will be used to develop an instructional model for implementing inquiry-based learning in introductory-level virtual laboratory courses. There are four levels of inquiry-based learning: confirmation experiments, structured inquiry, guided inquiry and open inquiry [14]. Although there is general consensus about the need for scaffolding, and the gradual removal of scaffolds for effective implementation of IBL, teaching practices vary widely within the literature. A model for designing and implementing an IBL-centric laboratory course in the early undergraduate program would therefore be an important contribution to this field of research in higher education.

\section{MethodS}

\subsection{Course structure}

The laboratory curriculum for a first-year biomedical engineering laboratory was designed to modulate student progression from structured- to open-inquiry. The course was comprised of four laboratory modules and a final design project. Throughout the course, students worked collaboratively in teams to complete laboratory submissions and design project deliverables. Students also worked individually to complete pre-laboratory assignments. The following is a schematic of the course and study structure (Figure 1).

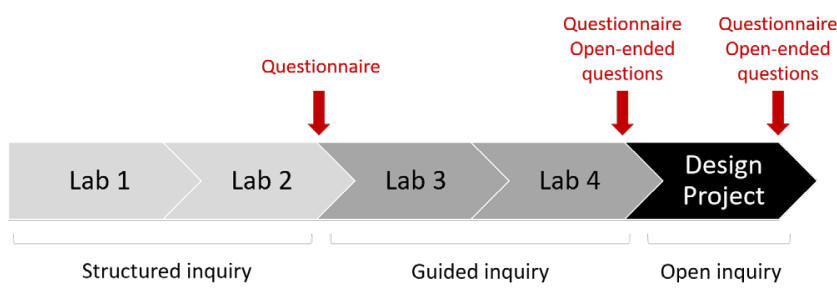

Figure 1. Schematic of course structure and evaluation methods.

A total of 108 students were registered in the course, and worked with a pre-assigned team throughout the term. Students located in international time zones were assembled into the same team, to allow for asynchronous team work to be arranged more easily.

The first two laboratory modules were highly structured (structured inquiry), in which students worked in teams to analyze experimental data collected from correct laboratory procedures. Experimental outcomes did not contain errors and did not deviate from expected outcomes. In pre-laboratory assignments, students were guided 
through a video demonstration of the correct laboratory procedure, and answered questions that prepared them for the team-based activity. Together, these activities aligned with a structured inquiry format.

In the two subsequent laboratory modules, students worked in teams to analyze experimental data collected from faulty laboratory procedures (guided inquiry). Experimental outcomes deviated from expected outcomes, and students were expected to propose reasons for unexpected results and methods to improve the experiment. In pre-laboratory assignments, students worked individually to identify faulty laboratory procedures from a video demonstration. Together, these activities aligned with a guided-inquiry format.

The final component of the laboratory course was a design project, which aligned with an open-inquiry structure. Students worked collaboratively to address an open-ended problem, without scaffolding assignments such as prelaboratory assignments.

\subsection{Data collection and analyses}

To explore students' perceptions of their self-regulated learning skills, quantitative analyses of survey responses and qualitative thematic content analysis of students' written reflections will be conducted. In the SRL surveys, student were asked to identify and rate to what extent they engaged in planning, monitoring and regulating strategies before, during and after lab activities. The SRL surveys were administered upon completion of each stage of inquiry-based learning: 1) structured inquiry, 2) guided inquiry, and 3) open inquiry. Some validity evidence for the internal structure of the survey will first be gathered using exploratory factor analytic methods to determine an appropriate number of subdomain and meaningful labels for these subdomains that are in line with the guiding theoretical SRL framework [13]. Descriptive statistics and inferential statistics using analysis of variance will then be conducted to compare changes in scores on the subdomains of the SRL survey and mean number of strategies employed across three pre-determined time-points across the semester.

Clusters of students based on different learning profiles may also be identified using SRL survey responses such as groups based on whether students' scores increased throughout the semester or not (e.g. Cluster that Improved/Did not improve). This would help to quantify the effects of open-inquiry curricular interventions in terms of the proportion of students' who improved on SRL over the semester.
For an in-depth understanding of students' cognitive, emotional and behavioural aspects of strategies employed, qualitative analyses of student reflections from before and after the open-inquiry lab activity will be conducted. Data will first be anonymized and responses will be considered in aggregate. Two members of the research team will conduct preliminary coding and analyses on the content of the reflection questions pertaining to the forethought, performance and self-reflection processes of the openinquiry lab activity. Open coding will be performed individually using researchers' independent perspectives to label instances of metacognitive, motivational processes and beliefs related to self-regulation as well as identifying instances of key processes utilized (eg. task analysis, goal setting, self-recording, self-evaluation) and variables that influence each of the SRL domains in the guiding theoretical framework. Successive rounds of open coding will inform preliminary categories. Data will be analyzed inductively (i.e. codes will be derived directly from the data), by reading through student reflections multiple times and considering important ideas, insights and evidence of self-regulation processes. These will be integrated systematically by using the constant comparative method [15] and higher-order categories will be developed. Coders will meet to review their analyses over several meetings to ensure intercoder reliability and through an iterative process, emerging themes will be identified. Representative themes as well as agreements/disagreements on thematic components will be identified and will be further elaborated and explored to facilitate the development of an overarching thematic framework that will summarize the data from student reflections into a coherent narrative. To this end, interpretation of themes and patterns pertaining to our research questions will be considered with respect to both the context of the activity and a comprehensive theoretical framework of SRL using a social cognitive perspective [13]. Constituent themes of our framework will then be applied to the reflection data set deductively in a final round of coding (guided by the consolidated framework) using a top-down approach. Discrepancies will be resolved over additional meetings and an audit trail will be maintained throughout the qualitative process.

\section{RESUlts}

Thus far, data has been collected from the first survey (108 participants, $100 \%$ participation), which was administered after completion of the structured inquiry laboratories. Students rated the frequency to which they used a selfregulating strategy. A 3-point scale was used, with a score of 1 indicating "rarely", a score of 2 indicating "sometimes" and a score of 3 indicating "oftentimes". A total of 7 survey questions were associated with the forethought phase, 8 were associated with the performance 
phase, and 5 questions were associated with the selfreflection phase. Overall, the average scores are similar across the three phases of self-regulated learning (Figure 2).

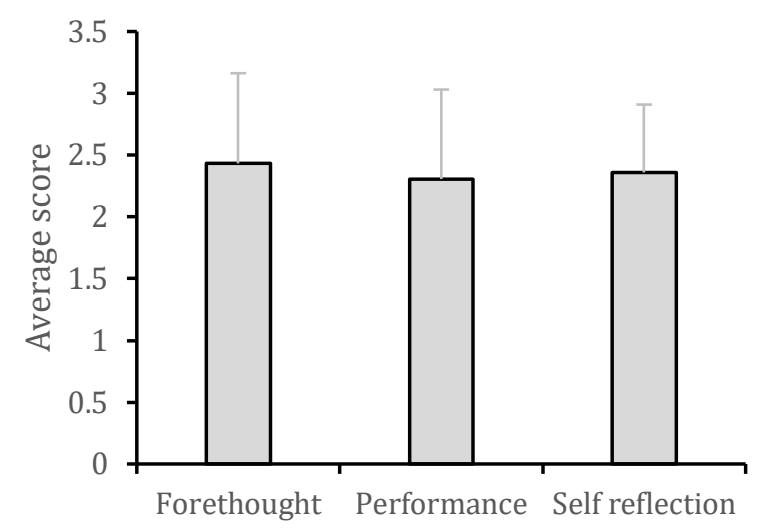

Figure 2. Average scores indicating the frequency to which students used self-regulated learning strategies in the forethought, performance and self reflection phases.

The average scores for each survey question associated with the forethought phase of self-regulation were determined (Figure 3).

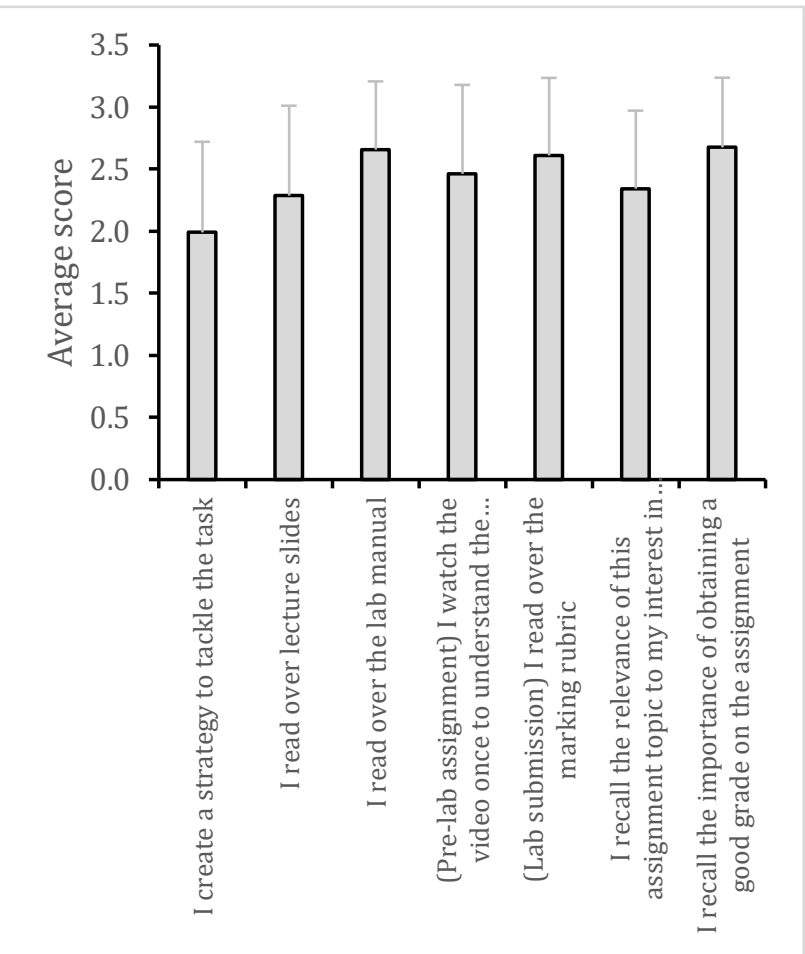

Figure 3. Average scores indicating the frequencies to which students used seven self-regulating strategies, prior to beginning a pre-lab assignment or lab submission.
The average scores for questions associated with the performance phase were also determined (Figure 4).

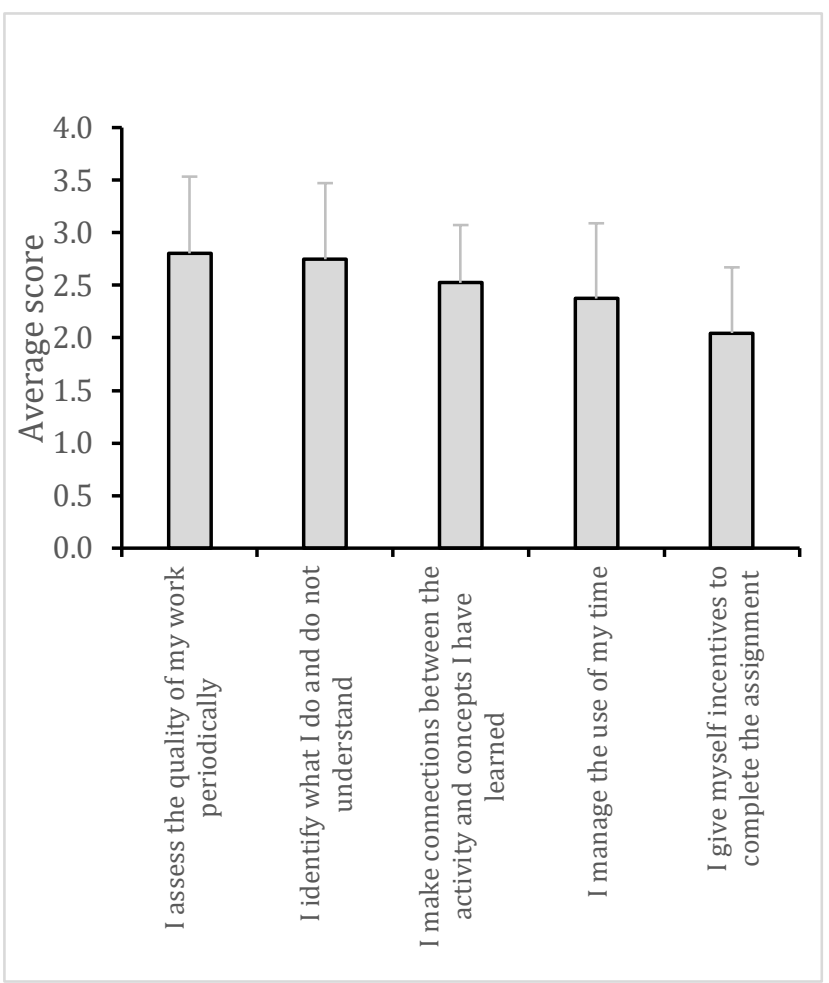

Figure 4. Average scores indicating the frequencies to which students used five self-regulating strategies, during the process of completing a pre-lab assignment or lab submission.

As part of the performance phase, students may activate help-seeking strategies when encountering challenges. The average scores related to help-seeking during the performance phase were determined (Figure 5).

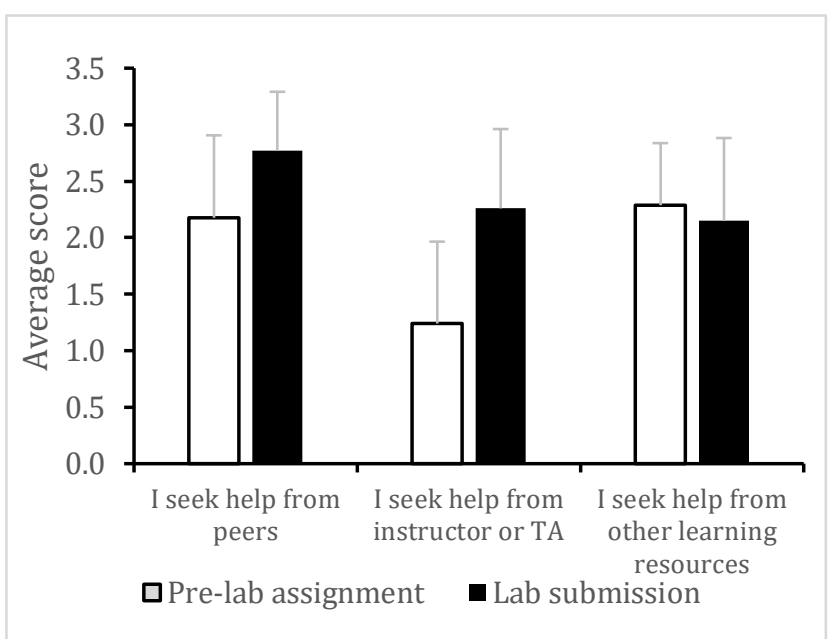


Figure 5. Average scores indicating the frequencies to which students used three help seeking strategies, when encountering challenges while completing a pre-lab assignment or lab submission.

Finally, average scores for questions associated with the self reflection phase were determined (Figure 6).

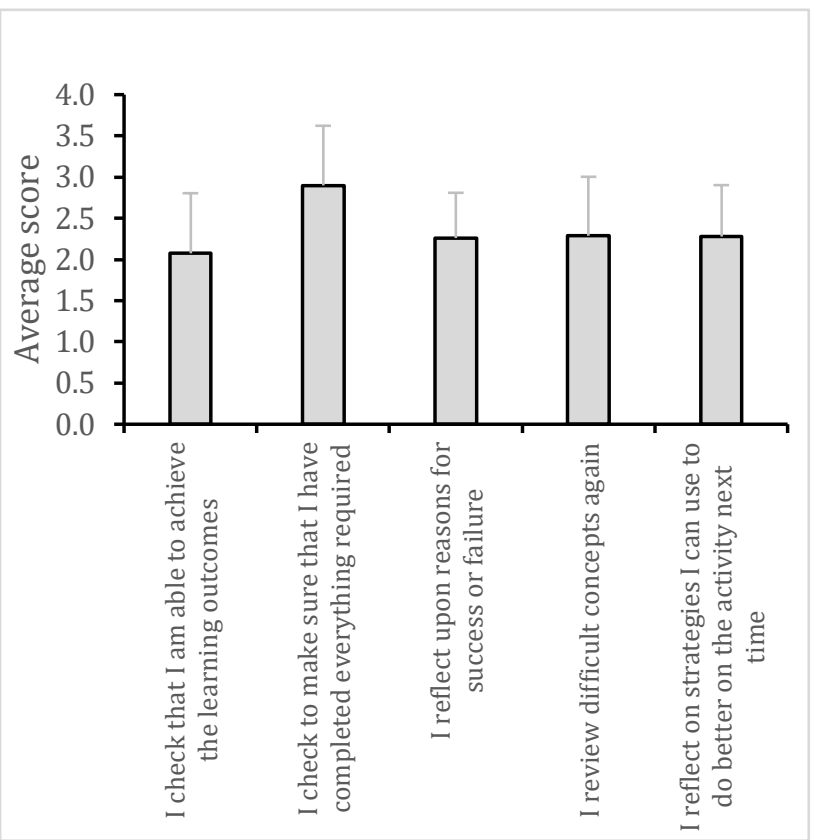

Figure 6. Average scores indicating the frequencies to which students used five self-regulating strategies, after completing a pre-lab assignment or lab submission.

\section{DISCUSSION}

The results presented thus far are preliminary, and conclusions cannot be made regarding changes in student use of self-regulating strategies throughout the course. However, some patterns are noteworthy and will be highlighted below.

Foremost, results from the forethought phase show that students frequently referred to course resources, including lecture notes, marking rubrics, and lab manuals, prior to beginning a learning task. Interestingly, students relied comparatively less on creating a strategy to approach the task. This is likely due to the structured nature of the learning activities, which have well defined learning outcomes and directives. It is hypothesized that students will be more actively involved in creating a strategy in less structured learning activities, such as the guided inquiry laboratory modules and open inquiry design project.

Of all strategies probed during the performance phase of a task, students reported a comparatively low frequency of involvement in time management and providing selfincentives to complete the task. In comparing help seeking strategies between pre-laboratory assignments and lab submissions, results suggest that students seek help more frequently from peers, instructors and teaching assistants when completing their lab submission, as compared to the pre-lab assignment. This is not surprising, given that the lab submission is completed as a team, while the pre-lab assignment is completed individually. Moreover, there is designated time during synchronous sessions for collaborative work on lab submissions, which provides students greater access to peers, the instructor and teaching assistants. On the contrary, pre-lab assignments are completed asynchronously, and require students to coordinate communication methods to seek help from other people.

Lastly, student scores from survey questions associated with the self reflection stage indicate that students frequently reflect by checking that all components are completed. However, other strategies for self-judgement and self-reaction are less frequently used. Again, this may be due to the structured nature of learning activities.

Currently, survey results obtained after guided inquiry laboratories (95 participants, 88\% participation) and the open inquiry design project (89 participants, 82\% participation), are being analyzed. Qualitative analyses of reflection assignments are currently underway. A complete comparison of results at other evaluation points in the study will better elucidate changes in student development of self-regulating skills throughout the course.

\section{References}

1. Weaver, G.C., Russell, C.B., Wink, D.J. (2008). Inquiry-based and research-based laboratory pedagogies in undergraduate science. Nature Chemical Biology, 4(10): 577-580.

2. Knutson, K., Smith, J. Wallert, M.A., Provost, J.J. (2010). Bringing the excitement and motivation of research to students; Using inquiry and research-based learning in a year-long biochemicstry laboratory. Biochemistry and Molecular Biology, 38(5): 324-329.

3. Demaria, M., Barry, A., Murphy, K. (2019). Using inquiry-based learning to enhance immunology laboratory skills. Frontiers in Immunology, 10: 1-5.

4. Kirkup, L., Varadharajan, M., Braun, M. (2016). A comparison of student and demonstrator 
perceptions of laboratory-based, inquiry-oriented learning experiences. International Journal of Innovation in Science and Mathematics Education, 24(2): 1-13.

5. Bhargava, P., Antonakakis, J., Cunningham, C., Zehnder, A.T. (2006). Web-based virtual torsion laboratory. Computer Applications in Engineering Education, 14(1): 1-8.

6. Darrah, M., Humbert, R., Finstein, J., Simon, M., Hopkins, J. (2014). Are virtual labs as effective as hands-on labs for undergraduate physics? A comparative study at two major universities. Journal of Science Education and Technology, 23:804-813.

7. Weisner, T.F., Lan, W. (2004) Comparison of student learning in physical and simulated unit operations experiments. Journal of Engineering Education, 93: 195-204.

8. Jong, T., Linn, M.C., Zacharia, Z.C. (2013). Physical and virtual laboratories in science and engineering education. Science, 340: 305-308.

9. Jeffrey, K.A., Bauer, C.F. (2020). Students' responses to emergency remote online learning teaching reveal critical factors for all teaching. Journal of Chemistry Education, 97: 2472-2485.

10. Jonassen, D. H., \& Hung, W. (2006). Learning to troubleshoot: A new theory-based design architecture. Educational Psychology Review, 18(1).

11. Zimmerman, B.J. (2000). Attaining selfregulation: A social cognitive perspective. In Boekaerts, M., Pintrich, P.R., Zeidner, M. (Eds), Handbook of Self-regulation (p. 13-39). Elsevier Inc.

12. Van de Bogart, K.L., Dounas-Frazer, D.R., Lewandowski, H.J., Stetzer, M.R. (2017). Investigating the role of socially mediated metacognition during collaborative troubleshooting of electric circuits. Physical Review Physics Education Research, 13: 020116-1-19.

13. Zimmerman, B.J., Moylan, A.R. (2009). Selfregulation: Where metacognition and motivation intersect. In Hacker, D.J., Dunlosky, J., Graesser, A.C. (Eds), The educational psychology series. Handbook of metacognition in education ( $\mathrm{p}$. 299-315). Routledge/Taylor \& Francis Group.
14. National Research Council (NRC). (2000). Inquiry and the National Science education Standards. Washington, D.C: National Academy Press.

15. Glaser BG. (1965). The Constant Comparative Method of Qualitative Analysis. Social Problems, 12(4): 436-45. 


\section{Appendix}

The following table summarizes the survey questions administered to students throughout the course.

Table A1: Summary of survey questions.

\begin{tabular}{|c|c|}
\hline SRL Phase & Question \\
\hline $\begin{array}{l}\text { Forethought } \\
\text { Prior to beginning } \\
\text { a pre-lab } \\
\text { assignment or lab } \\
\text { submission, I: }\end{array}$ & $\begin{array}{l}\text { 1. } \begin{array}{l}\text { Create a strategy to } \\
\text { tackle the task } \\
\text { 2. Read over lecture } \\
\text { slides }\end{array} \\
\text { 3. Read over lab manual } \\
\text { 4. (For pre-lab } \\
\text { assignment only) } \\
\text { Watch the video once } \\
\text { to understand the } \\
\text { scope of questions } \\
\text { asked } \\
\text { 5. } \begin{array}{l}\text { (For lab submission } \\
\text { only) Read over the } \\
\text { marking rubric }\end{array} \\
\text { 6. Recall the relevance } \\
\text { of this assignment } \\
\text { topic to my interest in } \\
\text { biomedical } \\
\text { engineering } \\
\text { 7. Recall the importance } \\
\text { of obtaining a good } \\
\text { grade on the } \\
\text { assignment }\end{array}$ \\
\hline $\begin{array}{l}\text { Performance } \\
\text { During the process } \\
\text { of completing a }\end{array}$ & $\begin{array}{l}\text { 1. Assess the quality of } \\
\text { my work periodically } \\
\text { (ex. checking my } \\
\text { work) }\end{array}$ \\
\hline
\end{tabular}

\begin{tabular}{|c|c|}
\hline $\begin{array}{l}\text { pre-lab assignment } \\
\text { or lab submission, } \\
\text { I: }\end{array}$ & $\begin{array}{l}\text { 2. Identify what I do and } \\
\text { do not understand } \\
\text { 3. Make connections } \\
\text { between the activity } \\
\text { and concepts I have } \\
\text { learned } \\
\text { 4. Manage the use of my } \\
\text { time } \\
\text { 5. Give myself } \\
\text { incentives to complete } \\
\text { the assignment }\end{array}$ \\
\hline $\begin{array}{l}\text { Performance: } \\
\text { When I encounter } \\
\text { challenges while } \\
\text { completing a pre- } \\
\text { lab video } \\
\text { assignment or lab } \\
\text { submission, I: }\end{array}$ & $\begin{array}{l}\text { 1. Seek help from peers } \\
\text { 2. Seek help from } \\
\text { instructor or TA } \\
\text { 3. Seek help from other } \\
\text { learning resources }\end{array}$ \\
\hline $\begin{array}{l}\text { Self reflection } \\
\text { After I have } \\
\text { completed a pre- } \\
\text { lab assignment or } \\
\text { lab submission, I: }\end{array}$ & $\begin{array}{l}\text { 1. Check that I am able } \\
\text { to achieve the learning } \\
\text { outcomes } \\
\text { 2. Check to make sure } \\
\text { that I have completed } \\
\text { everything required } \\
\text { 3. Reflect upon reasons } \\
\text { for success or failure } \\
\text { 4. Review difficult } \\
\text { concepts again } \\
\text { 5. Reflect on strategies I } \\
\text { can use to do better on } \\
\text { the activity next time }\end{array}$ \\
\hline
\end{tabular}

